\title{
The prognostic utility of the histologic subtype of stage I lung adenocarcinoma may be diminished when using only the invasive component to determine tumor size for tumor node metastasis (TNM) staging
}

\author{
Yeoun Eun Sung ${ }^{1 \wedge}$, Kyo Young Lee ${ }^{1 \wedge}$, Youngkyu Moon $^{2} \wedge$ \\ ${ }^{1}$ Department of Hospital Pathology, Seoul St. Mary's Hospital, College of Medicine, The Catholic University of Korea, Seoul, Republic of Korea; \\ ${ }^{2}$ Department of Thoracic \& Cardiovascular Surgery, Eunpyeong St. Mary's Hospital, College of Medicine, The Catholic University of Korea, Seoul, \\ Republic of Korea \\ Contributions: (I) Conception and design: Y Moon; (II) Administrative support: YE Sung, KY Lee; (III) Provision of study materials or patients: YE \\ Sung, KY Lee; (IV) Collection and assembly of data: All authors; (V) Data analysis and interpretation: Y Moon; (VI) Manuscript writing: All authors; \\ (VII) Final approval of manuscript: All authors. \\ Correspondence to: Youngkyu Moon, MD, PhD. Department of Thoracic \& Cardiovascular Surgery. Eunpyeong St. Mary's Hospital, College of \\ Medicine, The Catholic University of Korea, 1021, Tongil-ro, Eunpyeong-gu, Seoul 03312, Republic of Korea. Email: mykae@catholic.ac.kr.
}

\begin{abstract}
Background: Histologic subtypes were considered prognostic factors in early-stage lung adenocarcinoma in the $7^{\text {th }}$ edition of the tumor node metastasis (TNM) staging system (TNM-7). However, the T-staging system has changed and now measures only the size of the invasive component to determine tumor size. The aim of this study was to determine whether the histologic subtype is still a prognostic factor in the $8^{\text {th }}$ edition of the TNM staging system (TNM-8).

Methods: From 2010 to 2017, 788 patients who underwent curative surgery for stage I lung adenocarcinoma according to TNM-8 were analyzed retrospectively. Survival rates were compared among predominant patterns of adenocarcinoma. Prognostic factors were analyzed according to risk factors for recurrence in stage I lung adenocarcinoma.

Results: The 5-year recurrence-free survival rates among predominant histologic subtypes were statistically different, especially between the lepidic/acinar/papillary group and the micropapillary/solid group. Total tumor size was not significantly different between the two groups, but invasive component size was different (1.5 vs. $2.3 \mathrm{~cm}, \mathrm{P}<0.001)$. In the multivariate analysis that adopted total tumor size as a variable, visceral pleural invasion (VPI), lymphovascular invasion (LVI), and micropapillary-predominant adenocarcinoma were significant predictors for recurrence. Conversely, adenocarcinoma subtypes were not significant risk factors for recurrence in the multivariate analysis that adopted invasive component size as a variable.

Conclusions: The importance of adenocarcinoma subtype for prognosis may be reduced when only the invasive component of a tumor is used to determine tumor size, as described in the TNM-8 staging system.
\end{abstract}

Keywords: Lung adenocarcinoma; TNM staging system; tumor size

Submitted Dec 14, 2020. Accepted for publication Mar 25, 2021.

doi: $10.21037 /$ jtd-20-3509

View this article at: http://dx.doi.org/10.21037/jtd-20-3509

^ ORCID: Yeoun Eun Sung, 0000-0002-9408-0085; Kyo Young Lee, 0000-0001-9954-8583; Youngkyu Moon, 0000-0002-6875-6918. 


\section{Introduction}

Lung adenocarcinoma is the most common histologic type of primary lung cancer (1). According to the 2015 World Health Organization (WHO) classification of lung tumors, adenocarcinoma is classified into several subtypes (2). In the histologic classification system, the components of adenocarcinoma are classified into 5 major histopathologic categories on the basis of the growth pattern of the tumor cell: lepidic, acinar, papillary, micropapillary, and solid (3). Many studies adopting the $7^{\text {th }}$ edition of the tumor node metastasis (TNM) staging system (TNM-7) reported correlations between subtypes (histopathologic components of adenocarcinoma) and disease prognosis in early-stage lung cancer (4-9). However, it is not well studied whether histologic subtypes also impact prognosis in early-stage lung cancer according to the $8^{\text {th }}$ edition of the TNM staging system (TNM-8).

In TNM-8, tumor size measurement, which applies to the "T" description, has changed from TNM-7 (10-12). Previously, in TNM-7, total tumor size was measured and T-stage was determined by the maximum size of the total tumor. However, in TNM-8, T-stage is determined by the maximum size of the invasive component without the lepidic component. Therefore, since only the size of the invasive component (acinar, papillary, micropapillary, and solid components) reflects the T-stage in TNM-8, the prognostic effect of subtypes may not be the same as previously considered. We wanted to know if the effect of subtypes of adenocarcinoma on prognosis is still valid in the same stage of lung adenocarcinoma when adopting the criteria of TNM-8.

The purpose of this study was to evaluate the effects of adenocarcinoma subtypes on prognosis of stage I lung adenocarcinoma (according to TNM-8) after curative surgical treatment. Simply, we attempted to confirm whether the subtype of adenocarcinoma is still a significant prognostic factor in TNM-8, which adopted the invasive component size as the descriptor of the "T" category.

We present the following article in accordance with the STROBE reporting checklist (available at http://dx.doi. org/10.21037/jtd-20-3509).

\section{Methods}

\section{Patients}

The study was conducted in accordance with the Declaration of Helsinki (as revised in 2013). This study was approved by the institutional review board of Seoul St. Mary's Hospital at the Catholic University of Korea and individual consent was waived (Referral number: KC19RNSI0103). From 2010 to $2017,1,630$ consecutive patients at a tertiary hospital in Korea were diagnosed with non-small cell lung cancer (NSCLC) and underwent curative resection. Of those patients, 1,196 were diagnosed with lung adenocarcinoma. In none of the patients studied was resection incomplete or was preoperative chemotherapy or radiotherapy administered. Patients who had synchronous lung cancer were excluded from the study. We retrospectively enrolled 788 patients who were judged, according to the pathologic criteria listed in TNM-8 (pTNM), to have stage I lung adenocarcinoma including adenocarcinoma in situ (AIS), minimally invasive adenocarcinoma (MIA), and 5 major subtypes (lepidic, acinar, papillary, micropapillary, and solid-predominant) (2). We compared the recurrencefree survival (RFS) and disease-specific survival (DSS) rates among predominant subtypes of adenocarcinoma. We analyzed the risk factors for recurrence in stage I lung adenocarcinoma (according to TNM-8) after curative resection.

\section{Surgical procedures}

The standard surgical procedure for stage I lung cancer was anatomic resection (lobectomy or bilobectomy) with dissection of 3 or more mediastinal lymph node stations. The technique used for lymph node dissection was enbloc resection of the lymph nodes, including adjacent fat tissue. Sublobar resection was performed in the highrisk subgroup of patients who had a comorbid disease. In patients with a ground glass opacity (GGO) nodule located near the visceral pleura, intentional sublobar resection was considered with the patient's consent. In all patients who underwent sublobar resection, we obtained a sufficient resection margin in which the length was larger than the tumor diameter.

\section{Histological evaluation and re-staging according to TNM-8}

All pathological specimens were re-examined by pathologists and their observations were recorded. Each case was reviewed for tumor size, location, lymph node status, pleural invasion, and lymphovascular invasion (LVI). To describe the histologic patterns of tumors, the occupancy ratio of each histologic component (lepidic, acinar, papillary, micropapillary, and solid) in the total tumor area 
was measured and recorded semi-quantitatively in 5\% increments according to the 2015 WHO classification of lung tumors (2). We used the TNM staging system (pTNM) to establish the pathologic stage for each patient (13). To classify the "T" category using TNM-8, the tumor size was re-measured by the pathologist and the greatest dimension of the invasive component on pathologic study was recorded (10).

\section{Statistical analysis}

The Kaplan-Meier method was used to calculate the interval from surgery until the final follow-up visit, and the RFS and the DSS rates were calculated using confirmed recurrences and cancer-related deaths. We compared the clinicopathological characteristics of subtype groups. The student's $t$-test or Wilcoxon rank-sum test was used for continuous variables and Fisher's exact test or the $\chi^{2}$ test was applied for categorical variables. The RFS and DSS between both groups were compared using the log-rank test. In a multivariate analysis, the Cox proportional hazard model was used to determine the risk of recurrence for all patients. A P value less than 0.05 was considered statistically significant. Statistical analyses were performed using SPSS 24.0 software (IBM Corp., Armonk, NY, USA).

\section{Results}

The clinicopathological characteristics of all 788 study patients are shown in Table 1 . The mean age was $63.4( \pm 10.1)$ years, and there were more female $(59.5 \%)$ than male patients. Sublobar resection was conducted in 206 patients (26.1\%) and lobectomy (or bilobectomy) was conducted in 582 patients $(73.9 \%)$. Most surgery was performed using video-assisted thoracoscopic surgery (91.0\%). The postoperative complication rate was $12.8 \%$. The postoperative mortality rate was $0.1 \%$.

The numbers of patients with stage $0, \mathrm{IA} 1, \mathrm{IA} 2, \mathrm{IA} 3$, and IB according to TNM-8 were 38 (4.8\%), 319 (40.5\%), 207 (26.3\%), 69 (8.8\%), and 155 (19.7\%), respectively. AIS, MIA, and invasive adenocarcinoma were diagnosed in 38 (4.8\%), 141 (17.9\%), and 609 (77.3\%) patients, respectively. Among those with invasive adenocarcinoma, the numbers of patients with lepidic-, acinar-, papillary-, micropapillary-, and solid-predominant adenocarcinoma were $144(18.3 \%)$, 345 (43.8\%), 67 (8.5\%), 38 (4.8\%), and $15(1.9 \%)$, respectively. The mean tumor size, including the lepidic component, was $2.0 \mathrm{~cm}$ and the mean invasive component size was $1.2 \mathrm{~cm}$.

There were 49 cases of stage migration from TNM7 to TNM-8 (Table 2). Each of the stage migrations was a down-stage of the " $T$ " category. The changes were due to reductions in tumor size from total tumor size (including lepidic component) to invasive component size.

\section{Survival analysis of adenocarcinoma subtypes}

The median follow-up time for stage I lung adenocarcinoma was 1,006 days (range, 45-2,989 days). Recurrence was identified in 60 patients (Table 3).

We compared survival among adenocarcinoma subtypes. The 5-year RFS of AIS, MIA, lepidic-, acinar-, papillary-, micropapillary-, and solid-predominant adenocarcinoma were $100 \%, 100 \%, 87.1 \%, 82.8 \%, 91.9 \%, 64.6 \%$, and $71.2 \%$, respectively (Figure $1 A$ ). The 5 -year DSS of AIS, MIA, lepidic-, acinar-, papillary-, micropapillary-, and solid-predominant adenocarcinoma were $100 \%, 100 \%$, $96.5 \%, 93.1 \%, 100 \%, 90.9 \%$, and $87.2 \%$, respectively (Figure 1B). The RFS difference was significant between the two groups [lepidic-, acinar-, and papillary-predominant adenocarcinoma (LAP group) and micropapillary- and solid-predominant adenocarcinoma (MS group), $\mathrm{P}<0.001]$ (Figure 2A). The DSS was also different between the LAP and MS groups $(\mathrm{P}=0.011)$ (Figure $2 B)$.

We compared the clinicopathological characteristics of the LAP group and the MS group to evaluate factors that might influence survival difference in the two groups (Table 4). In the MS group, more male patients and more former or current smokers were included; pulmonary function was poorer in the MS group. More mediastinal lymph node dissection was performed in the LAP group. In terms of pathological characteristics, the MS group had more patients with high T-stages. Total tumor size was not significantly different between the two groups, but invasive tumor size was smaller in the LAP group $(1.5 v s .2 .3 \mathrm{~cm}$, $\mathrm{P}<0.001)$. The incidences of visceral pleural invasion (VPI) and LVI were also more frequent in the MS group $(\mathrm{P}=0.008$ and $\mathrm{P}=0.001$, respectively). As a result, the MS group had more factors that affected poor prognosis.

\section{Risk factors for recurrence in patients with stage I lung adenocarcinoma after curative lobectomy with mediastinal lymph node dissection}

We analyzed risk factors for recurrence. In order to reduce the recurrence effect of the surgical procedure, 
Table 1 Clinicopathological characteristics of patients $(n=788)$ with stage I lung adenocarcinoma after curative resection

\begin{tabular}{|c|c|}
\hline Variables & $\mathrm{N}(\%)$ or mean $( \pm \mathrm{SD})$ \\
\hline Age & $63.4( \pm 10.1)$ \\
\hline \multicolumn{2}{|l|}{ Sex } \\
\hline Male & $319(40.5)$ \\
\hline Female & $469(59.5)$ \\
\hline Former or current smokers & $231(29.3)$ \\
\hline FEV1 $(\%)( \pm S D)$ & $95.9( \pm 16.9)$ \\
\hline DLCO (\%) $( \pm S D)$ & $88.7( \pm 16.8)$ \\
\hline \multicolumn{2}{|l|}{ Involved lobes } \\
\hline Right upper & $271(34.4)$ \\
\hline Right middle & $76(9.6)$ \\
\hline Right lower & $153(19.4)$ \\
\hline Left upper & $172(21.8)$ \\
\hline Left lower & $116(14.7)$ \\
\hline \multicolumn{2}{|l|}{ Operation } \\
\hline Wedge resection & $111(14.1)$ \\
\hline Segmentectomy & $95(12.1)$ \\
\hline Lobectomy & $576(73.1)$ \\
\hline Bilobectomy & $6(0.8)$ \\
\hline \multicolumn{2}{|l|}{ Surgical approach } \\
\hline VATS & $717(91.0)$ \\
\hline Open thoracotomy & $71(9.0)$ \\
\hline \multicolumn{2}{|l|}{ Extent of Lymph node dissection } \\
\hline No mediastinal lymph node dissection & $128(16.2)$ \\
\hline Mediastinal lymph node sampling & $107(13.6)$ \\
\hline Mediastinal lymph node dissection & $553(70.2)$ \\
\hline Postoperative hospital stay (days) & $6.5( \pm 7.8)$ \\
\hline Postoperative complications & $101(12.8)$ \\
\hline Surgical mortality & $1(0.1)$ \\
\hline \multicolumn{2}{|l|}{ Stage (TNM-7) } \\
\hline Stage 0 & $38(4.8)$ \\
\hline Stage IA & $549(69.7)$ \\
\hline Stage IB & $196(24.9)$ \\
\hline Stage IIA & $3(0.4)$ \\
\hline Stage IIB & $2(0.3)$ \\
\hline
\end{tabular}

Table 1 (continued)
Table 1 (continued)

\begin{tabular}{|c|c|}
\hline Variables & $\mathrm{N}(\%)$ or mean $( \pm \mathrm{SD})$ \\
\hline \multicolumn{2}{|l|}{ Stage (TNM-8) } \\
\hline Stage 0 & $38(4.8)$ \\
\hline Stage IA1 & $319(40.5)$ \\
\hline Stage IA2 & $207(26.3)$ \\
\hline Stage IA3 & $69(8.8)$ \\
\hline Stage IB & $155(19.7)$ \\
\hline \multicolumn{2}{|c|}{ Histologic subtypes (predominant pattern) } \\
\hline Adenocarcinoma in situ & $38(4.8)$ \\
\hline Minimally invasive adenocarcinoma & $141(17.9)$ \\
\hline Invasive adenocarcinoma & $609(77.3)$ \\
\hline Lepidic adenocarcinoma & $144(18.3)$ \\
\hline Acinar adenocarcinoma & $345(43.8)$ \\
\hline Papillary adenocarcinoma & $67(8.5)$ \\
\hline Solid adenocarcinoma & $38(4.8)$ \\
\hline Micropapillary adenocarcinoma & $15(1.9)$ \\
\hline $\begin{array}{l}\text { Total tumor size (including lepidic } \\
\text { component) }\end{array}$ & $2.0( \pm 0.9)$ \\
\hline Invasive component size & $1.2( \pm 0.9)$ \\
\hline Number of dissected lymph nodes & $11.0( \pm 7.8)$ \\
\hline Visceral pleural invasion & $131(16.6)$ \\
\hline Lymphovascular invasion & $221(28.0)$ \\
\hline
\end{tabular}

$\mathrm{SD}$, standard deviation; FEV1, forced expiratory volume in 1 second; DLCO, diffusing capacity for carbon monoxide; VATS, video-assisted thoracoscopic surgery; TNM-7, $7^{\text {th }}$ edition of the tumor node metastasis staging system; TNM- $8,8^{\text {th }}$ edition of the tumor node metastasis staging system.

only patients who underwent lobectomy with mediastinal lymph node dissection were included in this analysis. Thus, we attempted to determine whether the subtypes of adenocarcinoma affected the prognosis.

A total of 473 patients underwent curative anatomical lobectomy with mediastinal lymph node dissection of more than 3 stations. The clinicopathological characteristics are shown in Table 5. Univariate and multivariate analyses were conducted to identify the prognostic factors using a Cox proportional hazard model (Table 6). Specific variables identified as significant $(\mathrm{P}<0.1)$ by univariate analysis included sex, smoking status, total tumor size, invasive component size, VPI, LVI, and adenocarcinoma subtypes. 
Table 2 Incidence of stage migration from TNM-7 to TNM-8 $(\mathrm{n}=750)$

\begin{tabular}{lc}
\hline TNM-7 to TNM-8 & Number \\
\hline Stage IB to stage IA & 44 \\
Stage IB to stage IA1 & 10 \\
Stage IB to stage IA2 & 9 \\
Stage IB to stage IA3 & 25 \\
Stage IIA to stage IA2 & 1 \\
Stage IIA to stage IB & 2 \\
Stage IIB to stage IA3 & 1 \\
Stage IIB to stage IB & 1 \\
\hline
\end{tabular}

TNM-7, $7^{\text {th }}$ edition of the tumor node metastasis staging system;

TNM-8, $8^{\text {th }}$ edition of the tumor node metastasis staging system.

Table 3 Summary of recurrence in stage I lung adenocarcinoma

\begin{tabular}{lc}
\hline Overall recurrence & $\mathrm{N}(\%)(\mathrm{n}=60)$ \\
\hline Locoregional recurrence & $34(56.7 \%)$ \\
Distant recurrence & $11(18.3 \%)$ \\
Both & $15(25.0 \%)$ \\
\hline
\end{tabular}

Locoregional: recurrence within ipsilateral hemithorax including pleura and mediastinal lymph nodes; Both: locoregional recurrence + distant recurrence.
These variables were entered into the multivariate model. We conducted two multivariate analyses: multivariate analysis $(\mathrm{T})$, which adopted total tumor size (including lepidic component) (Table 6, B), and multivariate analysis (I), which adopted invasive component size (Table 6, C). In multivariate analysis (T), VPI, LVI, and micropapillary adenocarcinoma were significant predictors for recurrence; adenocarcinoma subtypes were not significant risk factors for recurrence in multivariate analysis (I). In multivariate analysis (I), VPI [hazard ratio $(\mathrm{HR})=2.252, \mathrm{P}=0.010$ ] and LVI $(\mathrm{HR}=1.958, \mathrm{P}=0.029)$ were significant predictors of recurrence.

\section{Discussion}

The biggest change from TNM-7 to TNM-8 is in the classification of the "T" category. The T-stage is subdivided according to the size of the tumor, but the method of measuring the size of the tumor has not changed until the recent revision of the staging system. In the newly revised TNM-8, only the size of the invasive component, excluding the lepidic component, is measured to determine the T-stage. Therefore, in lung cancer, with the exception of adenocarcinoma, there is no change in tumor size with the new measurement system. However, in adenocarcinoma,
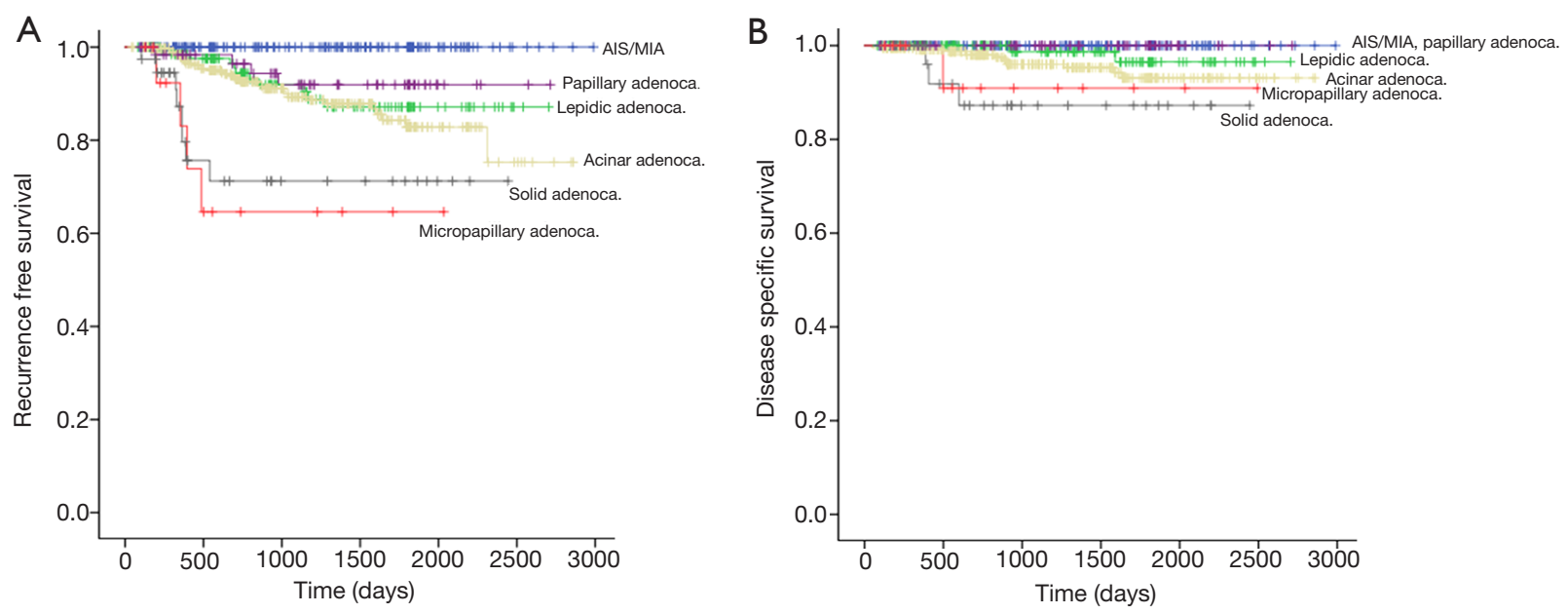

Figure 1 Comparison of RFS rate and DSS rate among subtypes of adenocarcinoma in patients with stage I lung adenocarcinoma after curative resection. (A) The 5-year RFS of AIS, MIA, lepidic-, acinar-, papillary-, micropapillary-, and solid-predominant adenocarcinoma were $100 \%, 100 \%, 87.1 \%, 82.8 \%, 91.9 \%, 64.6 \%$, and $71.2 \%$, respectively; (B) the 5-year DSS of AIS, MIA, lepidic-, acinar-, papillary-, micropapillary-, and solid-predominant adenocarcinoma were 100\%, 100\%, 96.5\%, 93.1\%, 100\%, 90.9\%, and 87.2\%, respectively. AIS, adenocarcinoma in situ; MIA, minimally invasive adenocarcinoma; RFS, recurrence-free survival; DSS, disease-specific survival. 

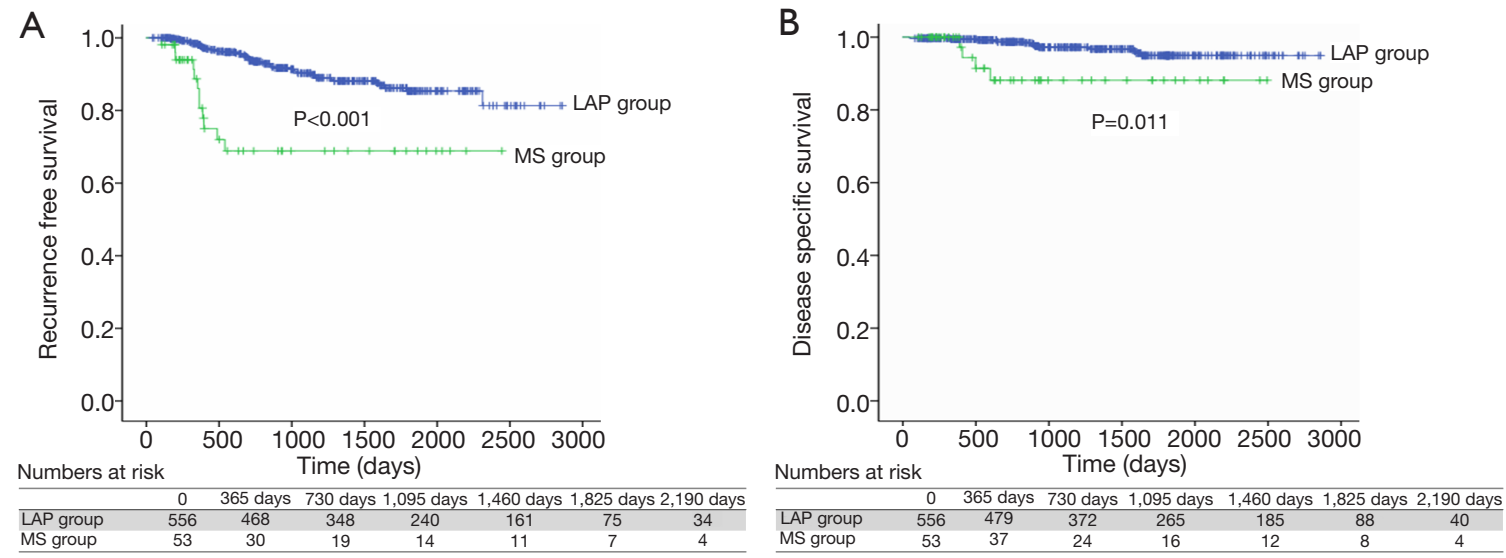

Figure 2 Comparison of RFS rate and DSS rate between the LAP group and the MS group. (A) The 5-year RFS of LAP group and MS group were $85.4 \%$ and $68.9 \%(\mathrm{P}<0.001)$; (B) the 5 -year DSS of LAP group and MS group were 94.9\% and 88.1\% $(\mathrm{P}=0.011)$. LAP group, lepidic adenocarcinoma + acinar adenocarcinoma + papillary adenocarcinoma; MS group, micropapillary adenocarcinoma + solid adenocarcinoma; RFS, recurrence-free survival; DSS, disease-specific survival.

Table 4 Comparison of clinicopathological characteristics between the LAP group and the MS group in patients with stage I lung adenocarcinoma* after curative resection

\begin{tabular}{|c|c|c|c|}
\hline Variables & LAP group $(n=556)$ & MS group $(n=53)$ & $P$ value \\
\hline Sex & & & 0.001 \\
\hline Male & $212(38.1)$ & $33(62.3)$ & \\
\hline Female & 344 (61.9) & $20(37.7)$ & \\
\hline FEV1 (\%) $( \pm S D)$ & $96.5( \pm 17.0)$ & $91.9( \pm 18.2)$ & 0.066 \\
\hline DLCO (\%) $( \pm S D)$ & $89.6( \pm 16.6)$ & $81.2( \pm 16.8)$ & 0.001 \\
\hline Involved lobes & & & 0.146 \\
\hline Right upper & $182(32.7)$ & $24(45.3)$ & \\
\hline Left upper & $122(21.9)$ & $13(24.5)$ & \\
\hline Left lower & $85(15.3)$ & $4(7.5)$ & \\
\hline Operation & & & 0.107 \\
\hline Wedge resection & $50(9.0)$ & $8(15.1)$ & \\
\hline Segmentectomy & $57(10.3)$ & $1(1.9)$ & \\
\hline Lobectomy & $443(79.7)$ & $44(83.0)$ & \\
\hline Bilobectomy & $6(1.1)$ & 0 & \\
\hline
\end{tabular}

Table 4 (continued) 
Table 4 (continued)

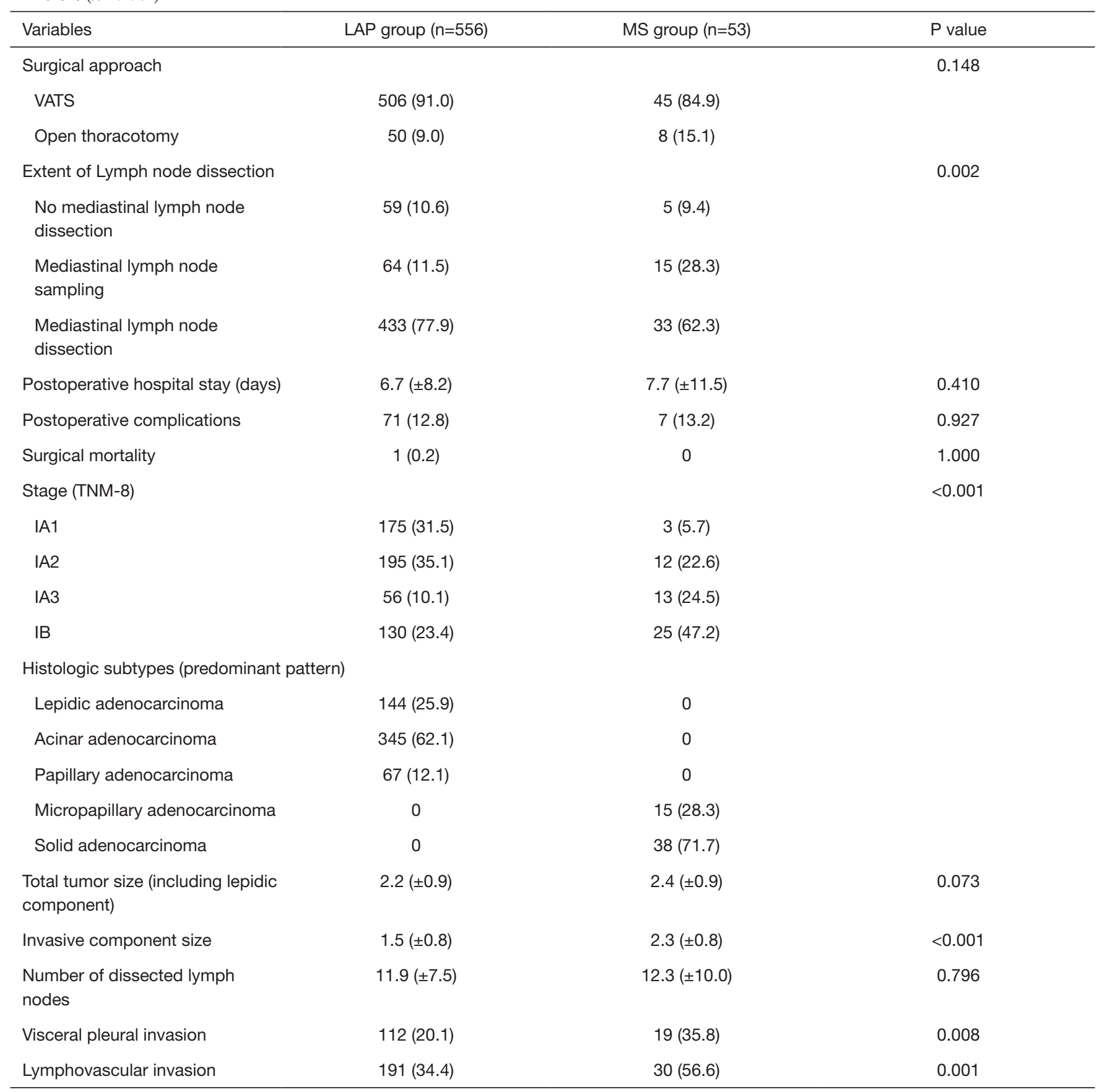

*, excluding adenocarcinoma in situ and minimally invasive adenocarcinoma. LAP group: lepidic adenocarcinoma, acinar adenocarcinoma, papillary adenocarcinoma; MS group: micropapillary adenocarcinoma, solid adenocarcinoma. SD, standard deviation; FEV1, forced expiratory volume in 1 second; DLCO, diffusing capacity for carbon monoxide; VATS, video-assisted thoracoscopic surgery; TNM-7, $7^{\text {th }}$ edition of the tumor node metastasis staging system; TNM-8, $8^{\text {th }}$ edition of the tumor node metastasis staging system. 
Table 5 Clinicopathological characteristics of patients $(n=473)$ with stage I lung adenocarcinoma* who underwent anatomical lobectomy with mediastinal lymph node dissection

\begin{tabular}{|c|c|}
\hline Variables & $\mathrm{N}(\%)$ or mean $( \pm \mathrm{SD})$ \\
\hline Age & $63.8( \pm 10.1)$ \\
\hline \multicolumn{2}{|l|}{ Sex } \\
\hline Male & $187(39.5)$ \\
\hline Female & $286(60.5)$ \\
\hline Former or current smokers & $140(29.6)$ \\
\hline FEV1 (\%) ( \pm SD) & $96.9( \pm 16.6)$ \\
\hline DLCO (\%) ( \pm SD) & $90.0( \pm 16.7)$ \\
\hline \multicolumn{2}{|l|}{ Involved lobes } \\
\hline Right upper & $174(36.8)$ \\
\hline Right middle & $47(9.9)$ \\
\hline Right lower & $95(20.1)$ \\
\hline Left upper & $97(20.5)$ \\
\hline Left lower & $60(12.7)$ \\
\hline \multicolumn{2}{|l|}{ Surgical approach } \\
\hline VATS & $435(92.0)$ \\
\hline Open thoracotomy & $38(8.0)$ \\
\hline Postoperative hospital stay (days) & $6.6( \pm 8.2)$ \\
\hline Postoperative complications & $64(13.5)$ \\
\hline Surgical mortality & 0 \\
\hline \multicolumn{2}{|l|}{ Stage (TNM-7) } \\
\hline Stage IA & $302(63.8)$ \\
\hline Stage IB & $166(35.1)$ \\
\hline Stage IIA & $3(0.6)$ \\
\hline Stage IIB & $2(0.4)$ \\
\hline \multicolumn{2}{|l|}{ Stage (TNM-8) } \\
\hline Stage IA1 & $118(24.9)$ \\
\hline Stage IA2 & $161(34.0)$ \\
\hline Stage IA3 & $65(13.7)$ \\
\hline Stage IB & $129(27.3)$ \\
\hline \multicolumn{2}{|l|}{$\begin{array}{l}\text { Histologic subtypes (predominant } \\
\text { pattern) }\end{array}$} \\
\hline Lepidic adenocarcinoma & $112(23.7)$ \\
\hline Acinar adenocarcinoma & $267(56.4)$ \\
\hline Papillary adenocarcinoma & $52(11.0)$ \\
\hline
\end{tabular}

Table 5 (continued)
Table 5 (continued)

\begin{tabular}{lc}
\hline Variables & $N(\%)$ or mean $( \pm$ SD) \\
\hline Solid adenocarcinoma & $29(6.1)$ \\
Micropapillary adenocarcinoma & $13(2.7)$ \\
Total tumor size (including lepidic & $2.3( \pm 0.9)$ \\
component) & $1.7( \pm 0.8)$ \\
Invasive component size & $14.9( \pm 6.9)$ \\
Number of dissected lymph nodes & $106(22.4)$ \\
Visceral pleural invasion & $180(38.1)$ \\
Lymphovascular invasion &
\end{tabular}

*, excluding adenocarcinoma in situ and minimally invasive adenocarcinoma. SD, standard deviation; FEV1, forced expiratory volume in 1 second; DLCO, diffusing capacity for carbon monoxide.

tumor size is changed with the new criteria. In stage I lung adenocarcinoma, a lepidic component is relatively common, so stage migration occurs because of the change in tumor size. In this study, tumor size was reduced in most stage I lung adenocarcinomas, and, in 49 patients, down-staging occurred. This is because only the size of the invasive component, not the lepidic component, was measured and the tumor size became smaller.

The lepidic component is considered a non-invasive component of adenocarcinoma. According to the 2015 WHO classification criteria, acinar, papillary, micropapillary, and solid components are classified as invasive components and are, therefore, differentiated from lepidic components. Hattori et al. reported that early-stage lung cancer with GGO has a better prognosis than earlystage lung cancer without GGO $(14,15)$. GGO represents a lepidic component in computed tomography images of the chest. Our previous studies also support results that confirm that a tumor that contains a lepidic component has a better prognosis than a tumor that does not contain a lepidic component $(16,17)$.

Many studies adopting TNM-7 criteria reported that adenocarcinoma subtypes were related with prognosis. In this study, survival rates differed among adenocarcinoma subtypes in stage I lung adenocarcinoma. The prognosis of lepidic-, acinar-, and papillarypredominant adenocarcinomas was better than solidand micropapillary-predominant adenocarcinomas. The survival rate graph shows the difference in the survival rate of each subtype (Figure 1). However, in the comparison of clinicopathological characteristics, micropapillary- and 
Table 6 Univariate and multivariate analyses of recurrence of stage I lung adenocarcinoma* after anatomical lobectomy with mediastinal lymph node dissection $(\mathrm{n}=473)$ (cox proportional hazard model)

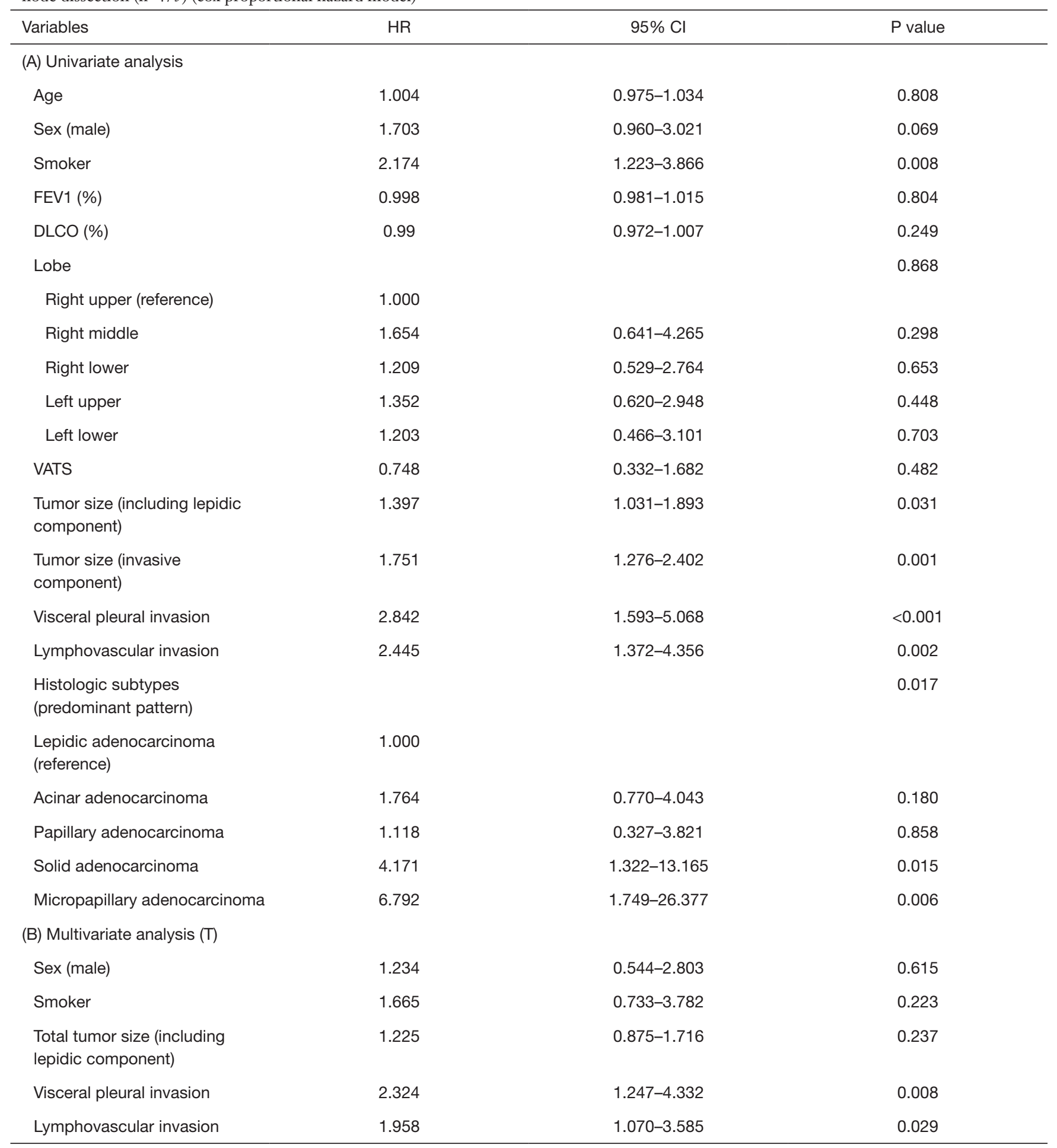

Table 6 (continued) 
Table 6 (continued)

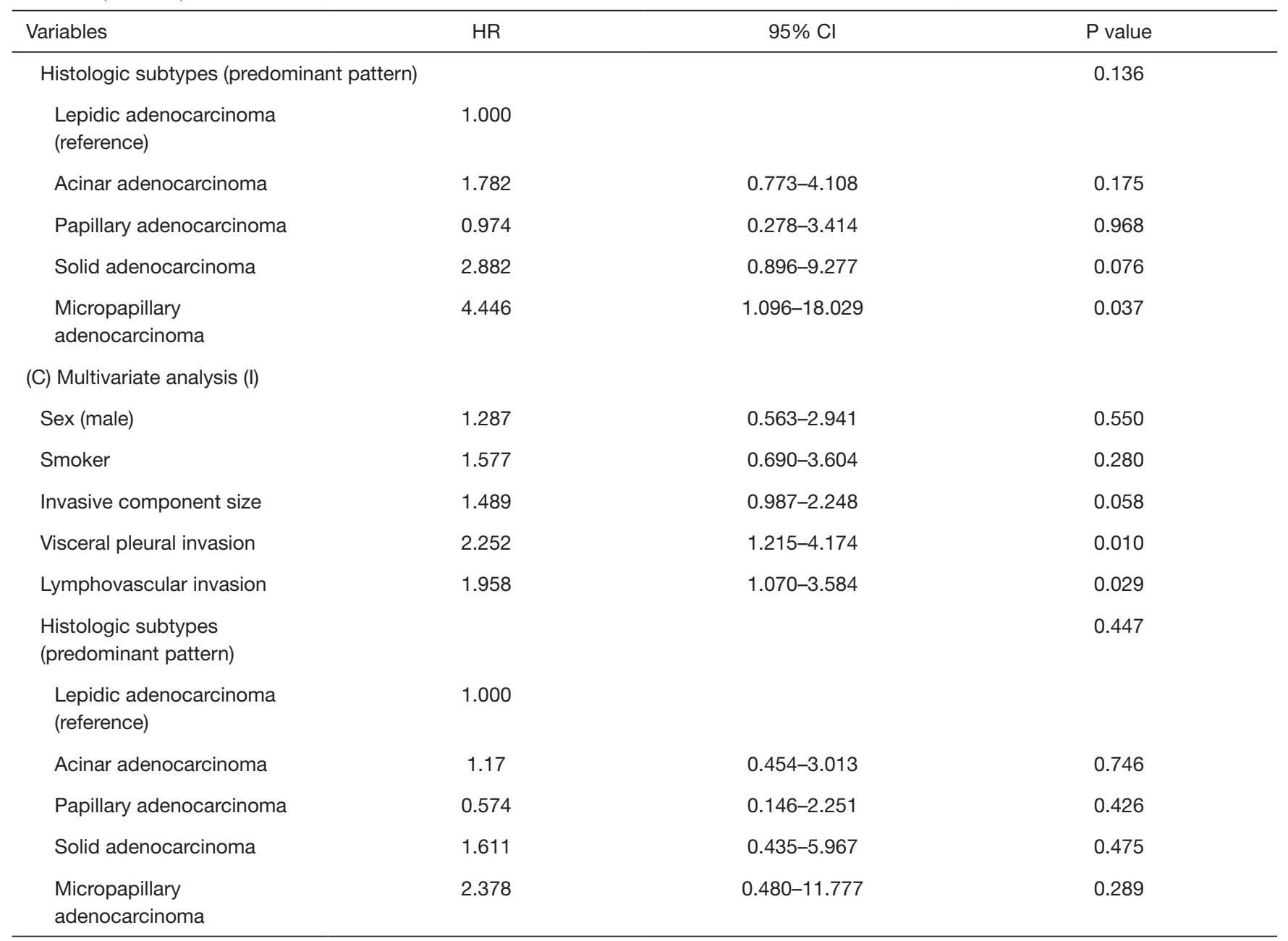

*, excluding adenocarcinoma in situ and minimally invasive adenocarcinoma. HR, hazard ratio; FEV1, forced expiratory volume in 1 second; DLCO, diffusing capacity for carbon monoxide; VATS, video-assisted thoracoscopic surgery.

solid-predominant adenocarcinoma had more characteristics that are considered poor prognostic factors. As shown in the comparison of the LAP group and the MS group (Table 4), there was no difference in total tumor size, but the invasive component size was significantly larger in the MS group. Thus, according to TNM-8, which further subdivides the T-stage according to the size of the invasive component, the frequencies of stage IA 3 and stage IB were higher in the MS group. The frequencies of VPI and LVI were also higher in the MS group. As a result, the survival rate difference among the subtypes was derived from the difference in the invasive tumor size and the invasiveness of the tumor. Since TNM- 8 reflects invasive tumor size, we found that the application of the current staging system might replace the significance of prognosis prediction through differences in subtypes.

Several studies reported that lymph node metastasis occurs more frequently in micropapillary and solid adenocarcinomas than in lepidic, acinar, and papillary adenocarcinomas $(9,18-20)$. We analyzed prognostic factors in patients who underwent anatomical lobectomy and mediastinal lymph dissection to exclude the possibility of occult lymph node metastasis. In the multivariate analysis, adenocarcinoma subtype was a significant risk factor for recurrence when we adopted total tumor size as a variable. However, adenocarcinoma subtype was not a significant 
risk factor for recurrence when the variable changed from total tumor size to invasive component size. As a result, adenocarcinoma subtypes were not significant prognostic factors when adjusted by invasive component size according to TNM-8, at least in Stage I lung cancer. VPI and LVI were significant risk factors for recurrence. VPI is a staging factor with the "T" category. Although LVI has some limitations including inter-observer discrepancy, the result suggests its potential as a prognostic factor in stage I lung cancer. Invasive component size, as a T-staging factor, also tends to relate with recurrence, but it did not have statistical significance in this study $(\mathrm{P}=0.058)$. If the number of samples was larger, we assume that the invasive component size would be a statistically significant factor.

Although there is currently no established histologic grading system, proposals have been made for grading according to predominant histologic patterns; lepidicpredominant as low grade, acinar- and papillarypredominant as intermediate grade and micropapillaryand solid-predominant as high grade, according to the 2015 WHO classification of lung tumors (2). Recently, difference in genomic characterization among predominant histologic subtypes of lung adenocarcinoma has been reported (21), which suggests possible explanation for prognostic difference. Also, a novel grading system has been proposed from the International Association for the Study of Lung Cancer Pathology Committee, based on RFS and overall survival, validated and tested in stage I to III (22). However, results of the current study show that when adjusted by invasive component size, the histologic patterns might not add any prognostic information to the $\mathrm{T}$ stage, at least in stage I lung adenocarcinoma. One of the possible explanations is that micropapillary and solid histologic patterns are relatively more infrequent in the earlier stage. For example, the percentages of micropapillary- and solidpredominant adenocarcinoma cases were $0.9 \%$ in T1a, $5.8 \%$ in T1b, $18.8 \%$ in T1c, $16.1 \%$ in T2a.

This study has several limitations. First, we used a retrospective study design. Second, the data were obtained from a single institution and the sample size was relatively small, especially in the MS group, so generalizing our result is difficult. However, the study patients were treated by a standardized surgical procedure at a tertiary hospital in Korea. Furthermore, a detailed analysis was possible because of the detailed data contained in the electronic medical records. We also used pathological specimens of all study patients for analysis. We thought that this study is the only study that has re-measured invasive component size using pathologic specimens of all study patients. We believe that our data can be used as the basis for future investigations. A larger study should be performed to validate our results.

In conclusion, predominant histologic subtypes of lung adenocarcinoma have been considered as prognosis factors, but their role as independent prognosticators may be diminished when applying measurement of invasive component size, at least in stage I according to TNM8. These findings might be different when investigating more advanced lung adenocarcinoma, including stage II, III and IV. In TNM-8, invasive component size and VPI are included in the "T" category and those two factors are more important than histologic subtypes of adenocarcinoma, which is also consistent with the results of our study. LVI also has a potential to be reflected in staging system as a prognostic factor in early0stage lung cancer. We expect further research to validate the current findings that may help establish a new grading system or staging in the future.

\section{Acknowledgments}

A native English-speaking professional (BioMed Proofreading, LLC) refined the written content.

Funding: This work was supported by the National Research Foundation of Korea (NRF) grant funded by the Korea government (MSIT) (No. 2019R1G1A1099670).

\section{Footnote}

Reporting Checklist: The authors have completed the STROBE reporting checklist. Available at http://dx.doi. org/10.21037/jtd-20-3509

Data Sharing Statement: Available at http://dx.doi. org/10.21037/jtd-20-3509

Conflicts of Interest: All authors have completed the ICMJE uniform disclosure form (available at http://dx.doi. org/10.21037/jtd-20-3509). YM reports grants from National Research Foundation of Korea (NRF), during the conduct of the study. The other authors have no conflicts of interest to declare.

Ethical Statement: The authors are accountable for all aspects of the work in ensuring that questions related to the accuracy or integrity of any part of the work are appropriately investigated and resolved. The study was conducted in accordance with the Declaration of Helsinki 
(as revised in 2013). This study was approved by the institutional review board of Seoul St. Mary's Hospital at the Catholic University of Korea and individual consent was waived (Referral number: KC19RNSI0103).

Open Access Statement: This is an Open Access article distributed in accordance with the Creative Commons Attribution-NonCommercial-NoDerivs 4.0 International License (CC BY-NC-ND 4.0), which permits the noncommercial replication and distribution of the article with the strict proviso that no changes or edits are made and the original work is properly cited (including links to both the formal publication through the relevant DOI and the license). See: https://creativecommons.org/licenses/by-nc-nd/4.0/.

\section{References}

1. Parkin DM, Ferlay J, Curado MP, et al. Fifty years of cancer incidence: CI5 I-IX. Int J Cancer 2010;127:2918-27.

2. Travis WD, Brambilla E, Nicholson AG, et al. The 2015 World Health Organization Classification of Lung Tumors: Impact of Genetic, Clinical and Radiologic Advances Since the 2004 Classification. J Thorac Oncol 2015;10:1243-60.

3. Travis WD, Brambilla E, Noguchi M, et al. International association for the study of lung cancer/american thoracic society/european respiratory society international multidisciplinary classification of lung adenocarcinoma. J Thorac Oncol 2011;6:244-85.

4. Zhang Y, Wang R, Cai D, et al. A comprehensive investigation of molecular features and prognosis of lung adenocarcinoma with micropapillary component. J Thorac Oncol 2014;9:1772-8.

5. Moon Y, Kim KS, Sung SW, et al. Correlation of histological components with tumor invasion in pulmonary adenocarcinoma. World J Surg Oncol 2014;12:388.

6. Kadota K, Villena-Vargas J, Yoshizawa A, et al. Prognostic significance of adenocarcinoma in situ, minimally invasive adenocarcinoma, and nonmucinous lepidic predominant invasive adenocarcinoma of the lung in patients with stage I disease. Am J Surg Pathol 2014;38:448-60.

7. Eguchi T, Kadota K, Park BJ, et al. The new IASLCATS-ERS lung adenocarcinoma classification: what the surgeon should know. Semin Thorac Cardiovasc Surg 2014;26:210-22.

8. Chao L, Yi-Sheng H, Yu C, et al. Relevance of EGFR mutation with micropapillary pattern according to the novel IASLC/ATS/ERS lung adenocarcinoma classification and correlation with prognosis in Chinese patients. Lung Cancer 2014;86:164-9.

9. Westaway DD, Toon CW, Farzin M, et al. The International Association for the Study of Lung Cancer/ American Thoracic Society/European Respiratory Society grading system has limited prognostic significance in advanced resected pulmonary adenocarcinoma. Pathology 2013;45:553-8.

10. Travis WD, Asamura H, Bankier AA, et al. The IASLC Lung Cancer Staging Project: Proposals for Coding T Categories for Subsolid Nodules and Assessment of Tumor Size in Part-Solid Tumors in the Forthcoming Eighth Edition of the TNM Classification of Lung Cancer. J Thorac Oncol 2016;11:1204-23.

11. Rami-Porta R, Asamura H, Travis WD, et al. Lung cancer - major changes in the American Joint Committee on Cancer eighth edition cancer staging manual. CA Cancer J Clin 2017;67:138-55.

12. Rami-Porta R, Eberhardt WEE. Clinical implications of the innovations in the primary tumour and metastasis of the 8(th) edition of the TNM classification for lung cancer. J Thorac Dis 2018;10:S2682-5.

13. Goldstraw P, Chansky K, Crowley J, et al. The IASLC Lung Cancer Staging Project: Proposals for Revision of the TNM Stage Groupings in the Forthcoming (Eighth) Edition of the TNM Classification for Lung Cancer. J Thorac Oncol 2016;11:39-51.

14. Hattori A, Hirayama S, Matsunaga T, et al. Distinct Clinicopathologic Characteristics and Prognosis Based on the Presence of Ground Glass Opacity Component in Clinical Stage IA Lung Adenocarcinoma. J Thorac Oncol 2019;14:265-75.

15. Hattori A, Matsunaga T, Takamochi K, et al. Importance of Ground Glass Opacity Component in Clinical Stage IA Radiologic Invasive Lung Cancer. Ann Thorac Surg 2017;104:313-20.

16. Moon Y, Sung SW, Lee KY, et al. The importance of the lepidic component as a prognostic factor in stage I pulmonary adenocarcinoma. World J Surg Oncol 2016;14:37.

17. Moon Y, Sung SW, Park JK, et al. Prognostic Factors of Pathological N1 Non-small Cell Lung Cancer After Curative Resection Without Adjuvant Chemotherapy. World J Surg 2019;43:1162-72.

18. Ye B, Cheng M, Li W, et al. Predictive factors for lymph node metastasis in clinical stage IA lung adenocarcinoma. Ann Thorac Surg 2014;98:217-23.

19. Moon Y, Lee KY, Kim KS, et al. Clinicopathologic 
correlates of postoperative $\mathrm{N} 1$ or $\mathrm{N} 2$ nodal upstaging in non-small cell lung cancer. J Thorac Dis 2016;8:79-85.

20. Moon Y, Kim KS, Lee KY, et al. Clinicopathologic Factors Associated With Occult Lymph Node Metastasis in Patients With Clinically Diagnosed N0 Lung Adenocarcinoma. Ann Thorac Surg 2016;101:1928-35.

21. Caso R, Sanchez-Vega F, Tan KS, et al. The Underlying

Cite this article as: Sung YE, Lee KY, Moon Y. The prognostic utility of the histologic subtype of stage I lung adenocarcinoma may be diminished when using only the invasive component to determine tumor size for tumor node metastasis (TNM) staging. J Thorac Dis 2021;13(5):2910-2922. doi: $10.21037 /$ jtd-20-3509
Tumor Genomics of Predominant Histologic Subtypes in Lung Adenocarcinoma. J Thorac Oncol 2020;15:1844-56.

22. Moreira AL, Ocampo PSS, Xia Y, et al. A Grading System for Invasive Pulmonary Adenocarcinoma: A Proposal From the International Association for the Study of Lung Cancer Pathology Committee. J Thorac Oncol 2020;15:1599-610. 